\title{
Simulated annealing optimization and experiments of a five-bar aerating mechanism for vertically aerating on salt-affected lands
}

\author{
Yifu Zhang ${ }^{1 *}$, Hongwen $\mathrm{Li}^{2}$, Ruihong Zhang ${ }^{1,3}$, Shuang Ding ${ }^{1}$ \\ (1. School of Mechanical Engineering, Yangzhou University, Yangzhou 225127, Jiangsu, China; \\ 2. College of Engineering, China Agricultural University, Beijing 100083, China; \\ 3. Jiangsu Engineering Center for Modern Agricultural Machinery and Agronomy Technology, Yangzhou University, Yangzhou 225127, \\ Jiangsu, China)
}

\begin{abstract}
Current agronomic improving treatments for soil salinization are faced with challenges of heavy workload, high cost, etc., which may seriously restrict agricultural productivity and sustainability on a large scale. Aerator has been applied to loosen soil and enhance soil permeability. In this research, aiming to realize vertically aerating, an aerator with a five-bar aerating mechanism was proposed to improve the aerating performance for saline-alkali land. The five-bar structure of aerating mechanism was designed based on analysis of the aerator on saline-alkali land. The kinematic model was established to describe the aerating process, and the key parameters of the aerating mechanism were obtained by satisfying the motion trajectory conditions. Subsequently, the related parameters were optimized by a simulated annealing method. Furthermore, numerical modeling was simulated to verify the perpendicularity performance after aerating head hitting into the soil. The simulation results indicated that the optimized five-bar aerating mechanism could decrease swinging extreme value by $24 \%$ compared with the initial parameters. Finally, the physical prototype of the aerator was tested in the field and performed as expected, producing $<7 \mathrm{~mm}$ depth tolerances and $<3.3^{\circ}$ angle tolerances, which met the design requirement.
\end{abstract}

Keywords: salinization, five-bar aerating mechanism, vertically aerating, simulated annealing method, computer simulation DOI: $10.25165 /$ j.ijabe.20211401.5322

Citation: Zhang Y F, Li H W, Zhang R H, Ding S. Simulated annealing optimization and experiments of a five-bar aerating mechanism for vertically aerating on salt-affected lands. Int J Agric \& Biol Eng, 2021; 14(1): 151-156.

\section{Introduction}

Soil salinization, a crucial process of soil degradation, has been a prominent problem in the ecological environment in the arid and semi-arid agricultural regions ${ }^{[1,2]}$. According to statistics, more than one billion $\mathrm{hm}^{2}$ areas are suffering from salt-affected soils, which are widely distributed in over one hundred countries around the world ${ }^{[3]}$. At the same time, climate change and human activities will also exacerbate the occurrence of secondary salinization. So the reclamation, same as the prevention for salt-affected soils, has become an important research hotspot for social economization and sustainable agricultural development.

Overviewing previous studies, numerous theoretical and applied researches have been implemented to ameliorate saline-alkali soils for increasing fertility and stimulating crop performance ${ }^{[4-6]}$, such as chemical stabilization, soil replacement, and agronomic methods. For instance, Chemical amendment is a common approach to provide a source of Calcium $\left(\mathrm{Ca}^{2+}\right)$ to substitute the exchangeable sodium $\left(\mathrm{Na}^{+}\right)$from the cation exchange complex, and then the replaced $\mathrm{Na}^{+}$can be leached from the root

\section{Received data: 2019-08-08 Accepted data: 2020-08-23}

Biographies: Hongwen $\mathbf{L i}, \mathrm{PhD}$, Professor, research interest: conservation agriculture, agriculture machine and equipment engineering, Email: lhwen@ cau.edu.cn; Ruihong Zhang, PhD, Professor, research interest: agricultural equipment, Email: zhang-rh@163.com; Shuang Ding, PhD, Lecturer, research interest: mechanical engineering, Email: sding@yzu.edu.cn.

*Corresponding author: Yifu Zhang, $\mathrm{PhD}$, Lecturer, research interest: conservation agriculture, agriculture machine and equipment engineering. School of Mechanical Engineering, Yangzhou University, No. 196, Huayangxilu, Hanjiang District, Yangzhou 225127, Jiangsu, China. Tel: +86-514-87978347, Email: zyfu@yzu.edu.cn. zone through irrigation ${ }^{[7]}$. In laboratory settings, the salt tolerance gene was tested to inhibit damage, as the antiporter gene-mediated $\mathrm{Na}^{+}$extrusion, and therefore enhanced salt tolerance ${ }^{[8,9]}$. Based on the gene experiment, the salt tolerance of crops such as rice (Oryza sativa L.), maize (Zea mays L.), and alfalfa (Medicago sativa L.) were studied in field to increase the productivity in saline-alkali soils ${ }^{[10-12]}$.

Furthermore, the potential values of agronomic and engineering measures have generally been confirmed in salt-affected lands. In details, closed drainage was documented to heighten the irrigation leaching, and thereby reduced the accumulation of salt in top soi ${ }^{[13]}$. During soil preparation, plowing loosened top soil and decreased moisture evaporation by cutting the capillary ${ }^{[14]}$. Moreover, subsoiling was also an efficient cultivation method for sodic soil because it reduced soil bulk density and improved root development ${ }^{[15]}$. Recently, the application of organic amendments, e.g. manure, compost and crop straw, have been widely used as a better restoration strategy ${ }^{[16-19]}$. However, the sustainable reclamation for saline lands based on the above measures is facing a severe challenge because of the heavy workload and high cost, which may increase production cost and limit its use on large scales.

Soil macropores, continuous pores in more than $50 \mu \mathrm{m}$ diameter, are considered as a primary pathway for water downward migration ${ }^{[20]}$. These pores mainly exist in the irregular structure such as intergranular pores, and root channels. Water tends to flow into macropores under saturated soil conditions ${ }^{[21]}$. Therefore, artificial macropores with fibrous fillings were created to enhance vertical infiltration ${ }^{[22]}$. Sand column experiments were introduced in coastal saline soil, which verified the positive impact on soil leaching and desalting ${ }^{[23]}$. Aeration, another type of artificial 
macropore without filling materials, was applied as effective management for grass areas and had been tested to promote root development and soil environment ${ }^{[24,25]}$. In order to apply aeration to saline-alkali soil reclamation, Zhang et al. ${ }^{[26]}$ designed a rear suspended passive aerator to loosen soil and enhance permeability. However, the five-bar aerating mechanism was less optimized because the verticality of aerated holes significantly affected the mechanical stability and subsequent farming practice. In this study, we focused on the parameter optimization of linkages. An aerator with five-bar aerating mechanism was developed, and the kinematic model was established to describe the aerating process. Parameters were derived to obtain a better perpendicularity condition by simulated annealing method, and computer simulation was carried out to evaluate the performance of optimized parameters. In addition, field experiments with a four-row aerating mechanism were conducted to verify the reasonability of the optimal linkages.

The objective of this study was to develop simulated annealing optimization for the five-bar aerating mechanism to improve vertical performance on salt-affected lands. This research can provide a theoretical reference for performance assessment and simulation analysis of aerating mechanism, as well as mechanized improvement for salt-affected soil.

\section{Configuration and working principle}

The configuration of the aerator was depicted in Figure 1. Note that the aerator was coupled to a tractor's three-point suspension, which was composed of frame, transmission, aerating device, passive device, and depth wheel. In a process, two operations should be completed simultaneously to achieve vertically aerating, i.e., aerating the soil and offsetting the horizontal deviation between aerator and soil. Thus, aerating efficiency was improved. Meanwhile, the utilization of the mechanism and the aerating property were optimized.

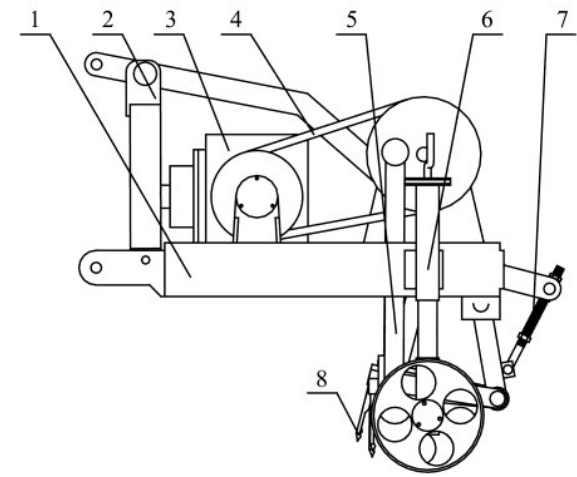

1. Frame 2. Suspension device 3. Transmission 4. Belt transmission

5. Aerating device 6. Depth wheel 7. Passive device 8. Aerating head Figure 1 Illustration of the aerator structure

The aerating device reciprocated up and down under the drive of rotating belt pulley, so as to realize continuous aerating. The passive device, constituted by support arm and spring, was an auxiliary unit to offset the horizontal deviation while aerating. Passive device worked in sequence as follows: when the aerating head was above the ground, the support arm maintained balance under the interaction of gravity and spring tension; when the perforating needle entered the soil, the horizontal resistance from soil pushed the aerating head to deflect support arm counterclockwise, the spring compressed while the tension increased during this process; after the aerating head was above the ground again, the horizontal resistance from soil disappeared, the compressed spring pushed the aerating head to deflect support arm clockwise to the initial position, the support arm maintained balance sequentially under the interaction of gravity and spring tension.

The aerating depth was firstly set as required by adjusting the depth wheel. When the tractor was working forward, the aerating device began to make holes circularly which was driven by the PTO of tractor (PTO drove the belt pulley to rotate). During the aerating process, the aerating device and passive device ran concertedly such that the operations of aerating soil and offsetting horizontal deviation were coordinated. Correspondingly, aerating device and passive device constituted the core mechanism, i.e., the aerating mechanism.

\section{Kinematic model establishment}

\subsection{Motion principle of aerating mechanism}

By considering the prescribed trajectory of the aerating head, the aerating mechanism was designed as a five-bar linkage. Assuming that each part of the mechanism was made of steel without elastic deformation, the gaps between rotations can be neglected $^{[27]}$. The original aerating mechanism was simplified as shown in Figure 2. Especially, the coordinate origin $B$ was established on the endpoint of the frame. In addition, the horizontal direction was set as the $x$-axis, and the $y$-axis represented the vertical direction. Furthermore, the whole unit moved horizontally at a uniform speed, and the direction was the reverse direction of the $x$-axis.

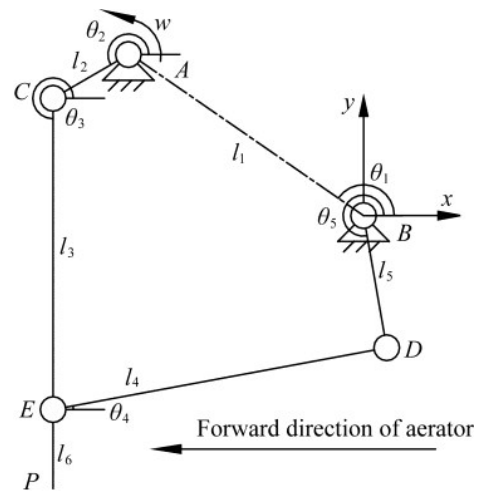

Figure 2 Motion diagram of aerating mechanism with five-bar linkage

The aerating mechanism with five-bar linkage consisted of a frame $A B$, crank $A C$, long rod $C E$, connecting rod $E D$, and support arm $B D$. The crank $A C$ was driven by belt transmission mechanism, thus the crank $A C$ could drive other bars. Furthermore, the aerating head $E P$ was consolidated linearly with long rod $C E$ such that aerating head $E P$ could move up and down in a plane with the rods $C E, E D$, and $B D$. Thus the aerating head $E P$ driven by the five-bar aerating mechanism moved in a particular trajectory to ensure vertical aerating and perpendicularity rate of the boreholes. The related parameters were presented in Table 1 .

\subsection{Displacement analysis}

The kinematic principle of five-bar aerating mechanism indicated that closed-loop equation was suitable for the kinematic chain established in $O-x y$. So the vector equation is established as Equation (1).

$$
\overrightarrow{D L}=\overrightarrow{D A}+\overrightarrow{A C}+\overrightarrow{\mathrm{CL}}+\overrightarrow{\mathrm{EN}}
$$

From the above results, Equations (2)-(5) are deduced as below. 
Table 1 Definition of related parameters of the aerating mechanism

\begin{tabular}{cl}
\hline Parameters & \multicolumn{1}{c}{ Explanation of related parameters } \\
\hline$l_{1}$ & The length of frame $A B / \mathrm{mm}$ \\
$l_{2}$ & The length of crank $A C / \mathrm{mm}$ \\
$l_{3}$ & The length of long rod $C E / \mathrm{mm}$ \\
$l_{4}$ & The length of connecting rod $E D / \mathrm{mm}$ \\
$l_{5}$ & The length of support arm $B D / \mathrm{mm}$ \\
$l_{6}$ & The length of aerating head $E P / \mathrm{mm}$ \\
$\theta_{1}$ & The installing angle of frame $A B /\left(^{\circ}\right)$ \\
$\theta_{2}$ & The angular displacement of crank $A C /\left(^{\circ}\right)$ \\
$\theta_{3}$ & The angular displacement of long rod $C E /\left(^{\circ}\right)$ \\
$\theta_{4}$ & The angular displacement of connecting rod $E D /\left(^{\circ}\right)$ \\
$\theta_{5}$ & The angular displacement of support $\operatorname{arm} B D /\left(^{\circ}\right)$ \\
$w$ & The angular velocity of crank $A C / \mathrm{r} \cdot \min { }^{-1}$ \\
\hline
\end{tabular}

Equation (2) describes the $A$-point displacement.

$$
\left\{\begin{array}{l}
x_{A}=x_{B}+l_{1} \cos \theta_{1} \\
y_{A}=y_{B}+l_{1} \sin \theta_{1}
\end{array}\right.
$$

Equation (3) describes the $C$-point displacement.

$$
\left\{\begin{array}{l}
x_{C}=x_{A}+l_{2} \cos \theta_{2} \\
y_{C}=y_{A}+l_{2} \sin \theta_{2}
\end{array}\right.
$$

The $E$-point displacement was expressed as Equation (4).

$$
\left\{\begin{array}{l}
x_{E}=x_{C}+l_{3} \cos \theta_{3} \\
y_{E}=y_{C}+l_{3} \sin \theta_{3}
\end{array}\right.
$$

According to the closed-loop principle, the $D$-point displacement could be obtained as Equation (5).

$$
\left\{\begin{array}{l}
x_{D}=x_{E}+l_{4} \cos \theta_{4}=l_{5} \cos \theta_{5} \\
y_{D}=y_{E}+l_{4} \sin \theta_{4}=l_{5} \sin \theta_{5}
\end{array}\right.
$$

Note that $B$-point was the coordinate origin, so $x_{B}=y_{B}=0$. In addition, as the power source of aerating mechanism, the crank $A C$ rotated at a constant revolving speed $w$, so the angular displacement of crank $A C$ could be expressed as:

$$
\theta_{2}=\theta_{0}+w t
$$

where, $\theta_{0}$ represents the initial angular displacement of crank $A C$, $\left({ }^{\circ}\right)$.

After the aerating head hitting the soil, five-bar aerating mechanism was performed by the combinational operation of the aerating device, passive device and the soil. The soil kept the aerating head relatively motionless in the horizontal direction, and synchronously the passive device (support arm BD) rotated counterclockwise to offset the horizontal deviation between the aerator and soil. Let the forward speed of the aerator be $v$, and the trajectory of $E$-point changed with time $t$ could be expressed as Equation (7).

$$
\left\{\begin{array}{l}
x_{E}=x_{C}+l_{3} \cos \theta_{3}+v t \\
y_{E}=y_{C}+l_{3} \sin \theta_{3}
\end{array}\right.
$$

The swing characteristic of aerating head $E P$ (i.e. long rod $C E$ ) was an important factor affecting perpendicularity performance, because the excessive swing led to unreasonable vibration, and thereby reduced holes' verticality. Let $\eta$ be the angle between aerating head EP and the positive direction of $x$-axis, variable $\eta$ can be expressed as Equation (8).

$$
\eta=\arccos \frac{x_{C}-x_{E}}{l_{3}}, \eta \in\left(0^{\circ}, 180^{\circ}\right)
$$

During the aerating process, the aerating head EP swung left and right in the vertical direction, which meant that variable $\eta$ values changed around $90^{\circ}$. Meanwhile, the variable $\eta$ is closer to $90^{\circ}$, the better the verticality of aerated holes. In this study, we aimed to describe the verticality perforation of aerating by analyzing the changes of variable $\eta$ and to establish the objective function around variable $\eta$ to realize the optimal design of the five-bar aerating mechanism.

\section{Simulated annealing optimization design}

\subsection{Variable analysis}

A series of related parameters should be derived to ensure that the aerating mechanism works with a high perpendicularity rate. Furthermore, by optimizing the rod length of the five-bar aerating mechanism, the angle (variable $\eta$ ) between aerating head EP (also the long rod $C E$ ) and the horizontal direction is set to be as close to $90^{\circ}$ as possible during the aerating process. Based on reference [26], let $l_{1}=420 \mathrm{~mm}, l_{2}=75 \mathrm{~mm}, \theta_{1}=111^{\circ}, \theta_{0}=160.6^{\circ}, w=250 \mathrm{r} / \mathrm{min}$, and time $t$ is the control variable. Therefore, the variables were determined as $X=[x(1), x(2), x(3), x(4)]=\left(l_{3}, l_{4}, l_{5}, v\right)$.

\subsection{Objective function}

In order to obtain a high perpendicularity rate, the angle $\eta$ between long rod $C E$ and the positive direction of $x$-axis should fluctuate as close as possible to $90^{\circ}$. In other words, the maximum absolute value of the difference between $\eta$ and $90^{\circ}$ should be the smallest during the aerating process.

The dynamic feature of the variable $\eta$ within one cycle was researched as the study object since the angle $\eta$ changed periodically in the working process. The angular displacement $\theta_{2}$ of crank $A C$ was discretized at intervals of $\pi / 180$ (the arc unit corresponding to $1^{\circ}$ ), then each element in $\theta_{2}(i)$ corresponds to a $\eta(i)$ value. Therefore, the mathematical expression for the objective function was: $\min \left\{\max \left(\left|\eta(i)-90^{\circ}\right|\right)\right\}$.

\subsection{Constraints condition}

In order to achieve aerating, the aerating mechanism in Figure 2 should satisfy the conditions that the bars $C E$ and $E D$ could not be aligned linearly (i.e., $\angle C E D=180^{\circ}$ and $\angle C E D=360^{\circ}$ ), and the bars $E D$ and $D B$ couldn't be aligned linearly (i.e., $\angle E D B=180^{\circ}$ and $\angle E D B=360^{\circ}$ ). Otherwise, there were dead-points that prevented the mechanism from further moving. That is to say, point $C, E$, and $D$ should constitute a triangle, and point $E, D$, and $B$ should constitute a triangle, so the length of $C D$ meet the following condition:

$$
\left|l_{3}-l_{4}\right|<L_{\mathrm{CD}}<l_{3}+l_{4}
$$

The length of $E B$ meet the following condition:

$$
\left|l_{4}-l_{5}\right|<L_{B E}<l_{4}+l_{5}
$$

Therefore, the constraints condition for objective function were

$$
\left\{\begin{array}{l}
(x(1)-x(2))^{2}-\left(l_{1} \cos \theta_{1}+l_{2} \cos \theta_{2}-x(3) \cos \theta_{5}\right)^{2}-\left(l_{1} \sin \theta_{1}+l_{2} \sin \theta_{2}-x(3) \sin \theta_{5}\right)^{2}<0 \\
\left(l_{1} \cos \theta_{1}+l_{2} \cos \theta_{2}-x(3) \cos \theta_{5}\right)^{2}+\left(l_{1} \sin \theta_{1}+l_{2} \sin \theta_{2}-x(3) \sin \theta_{5}\right)^{2}-(x(1)+x(2))^{2}<0 \\
(x(2)-x(3))^{2}-\left(l_{1} \cos \theta_{1}+l_{2} \cos \theta_{2}+x(1) \cos \theta_{3}\right)^{2}-\left(l_{1} \sin \theta_{1}+l_{2} \sin \theta_{2}+x(1) \sin \theta_{3}\right)^{2}<0 \\
\left(l_{1} \cos \theta_{1}+l_{2} \cos \theta_{2}+x(1) \cos \theta_{3}\right)^{2}+\left(l_{1} \sin \theta_{1}+l_{2} \sin \theta_{2}+x(1) \sin \theta_{3}\right)^{2}-(x(2)+x(3))^{2}<0
\end{array}\right.
$$

\subsection{Solution for objective function}

The simulated annealing optimization method that can realize global optimization was performed which can avoid the optimization process falling into the local optimal solution. The 
simulannealbnd function in the optimization toolbox of Matlab software was adopted to solve the simulated annealing problem, and the calling format was:

$$
[x, \mathrm{fval}]=\left(@ \text { fun, } x_{0}, \mathrm{lb}, \mathrm{ub}\right)
$$

where, $x$ is the optimal solution of objective function; fval is the function value of objective function at the optimal solution; @ fun is the function file name that called the objective function; $x_{0}$ is the initial vector of variable; $\mathrm{lb}$ and $\mathrm{ub}$ are the lower and upper limits of variables, respectively.

Through the iterative operation, the optimal solution was found as $x=(629.9990,270.0789,223.7014,1.1933)$, and the function value corresponding to the optimal solution was $f v a l=(1.6376)$. Therefore, the optimal length of long $\operatorname{rod} C E l_{3}=630 \mathrm{~mm}$, the optimal length of connecting rod $E D l_{4}=270 \mathrm{~mm}$, and the optimal length of support arm $B D l_{5}=224 \mathrm{~mm}$.

\section{Computer simulation}

The verticality of the aerated holes was an important index to evaluate aerating performance during the working process of the five-bar aerating mechanism. Thus, a numerical model was established to describe the perpendicularity performance after aerating head hitting into the soil, and the purpose of computer simulation was to analyze the dynamic characteristic of the variable $\eta$ as affected by the optimized parameters and forward speed.

Figure 3 compared the characteristic curve of variable $\eta$ during the aerating process under the forward speed of $4 \mathrm{~km} / \mathrm{h}$ for initial parameters and optimized parameters of the five-bar aerating mechanism. Overall, there appeared to be a similar trend of variable $\eta$, which increased firstly, then decreased, and finally increased again. Under initial parameters' condition, the value of $\eta$ fluctuated in the range of $87.5^{\circ}$ to $92.2^{\circ}$, while it fluctuated from $88.1^{\circ}$ to $91.9^{\circ}$ under optimized parameters' condition. During the process of aerating soil, the aerating head $E P$ swung from vertical direction between $-2.5^{\circ}$ to $2.2^{\circ}$ with initial parameters and from $-1.9^{\circ}$ to $1.9^{\circ}$ with optimized parameters. These results indicated that the optimized five-bar aerating mechanism could decrease swinging extreme value by $24 \%$ compared with the initial parameters.

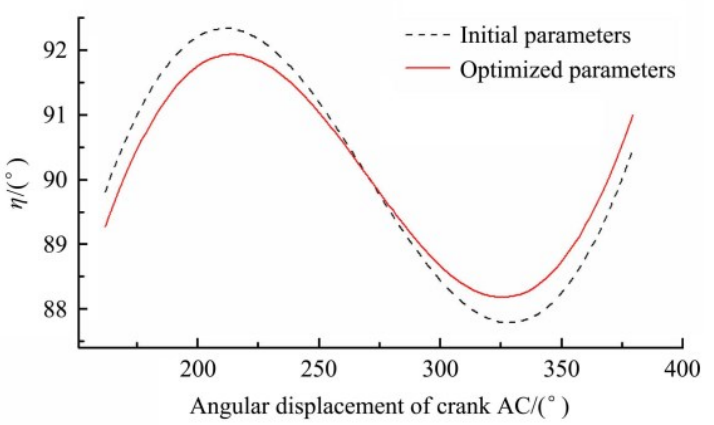

Note: Variable $\eta$ symbolized the angle between aerating head EP and the positive direction of $x$-axis

Figure 3 Characteristic curve of variable $\eta$ in an aerating process under the forward speed of $4 \mathrm{~km} / \mathrm{h}$ for initial parameters and optimized parameters of five-bar aerating mechanism

According to the description of objective function, the maximum absolute value of the difference between variable $\eta$ and $90^{\circ}$ should be the smallest in an aerating process. Let swinging characteristic of aerating head $E P$ from vertical be the difference between variable $\eta$ and $90^{\circ}$, thus the extreme value of swinging could reflect the inclination characteristic of the aerated holes.
Figure 4 depicted the dynamic swinging characteristic in an aerating process for optimized five-bar aerating mechanism. The simulation of perpendicularity performance for the aerated holes was run under 5 forward speeds of $3.5 \mathrm{~km} / \mathrm{h}, 3.7 \mathrm{~km} / \mathrm{h}, 4.0 \mathrm{~km} / \mathrm{h}$, $4.3 \mathrm{~km} / \mathrm{h}$, and $4.7 \mathrm{~km} / \mathrm{h}$, respectively. For all the forward speed treatments, the swinging value appeared to be a sinusoidal trend, which increased firstly, then decreased, and finally increased again. In addition, the maximal value and minimal value both increased with the increase of forward speed. Under the forward speed of $3.5 \mathrm{~km} / \mathrm{h}$ treatment, the swinging value fluctuated in the range of $-3.25^{\circ}$ to $1.5^{\circ}$, while it fluctuated from $-2.6^{\circ}$ to $1.6^{\circ}$, from $-1.8^{\circ}$ to $1.9^{\circ}$, from $-0.9^{\circ}$ to $2.1^{\circ}$, from $-0.7^{\circ}$ to $3.5^{\circ}$ under the forward speed of $3.7 \mathrm{~km} / \mathrm{h}, 4.0 \mathrm{~km} / \mathrm{h}, 4.3 \mathrm{~km} / \mathrm{h}$, and $4.7 \mathrm{~km} / \mathrm{h}$ treatment, respectively. The results indicated that the swing extreme value did not exceed $3.5^{\circ}$ when the aerator's forward speed was in the range of $3.5 \mathrm{~km} / \mathrm{h}$ to $4.7 \mathrm{~km} / \mathrm{h}$, and the closer the forward speed was to the optimal speed $(4 \mathrm{~km} / \mathrm{h})$, the smaller the swing extreme value.

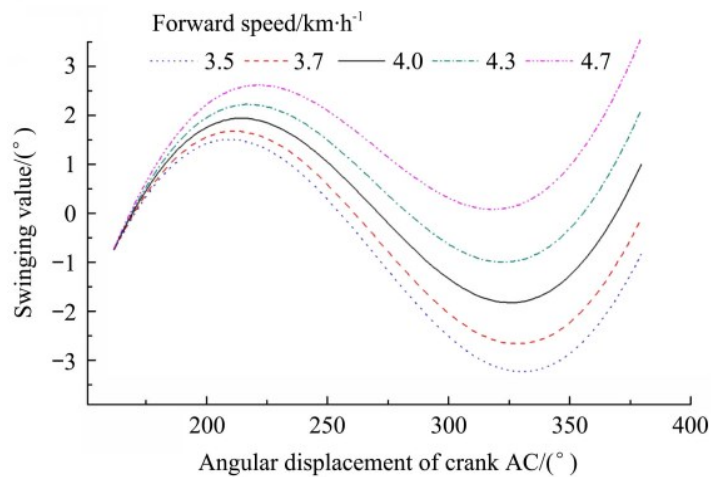

Note: The swinging value was the difference between variable and $90^{\circ}$ that was the inclination angle of the aerating head EP to the vertical direction.

Figure 4 Swinging characteristic of aerating head EP from

vertical in an aerating process for optimized five-bar aerating mechanism under different forward speed

\section{Field test}

\subsection{Experimental site}

The aerating experiments using the aerator with a four-row optimized five-bar aerating mechanism were conducted in August 2016, as shown in Figure 5. The experimental plot was located in Heze City $\left(35^{\circ} 50^{\prime} \mathrm{N}, 115^{\circ} 59^{\prime} \mathrm{E}\right)$, Shandong, China. Soils are defined as silt loam according to the USDA texture classification system with a bulk density of $1.35 \mathrm{~g} / \mathrm{cm}^{3}$.

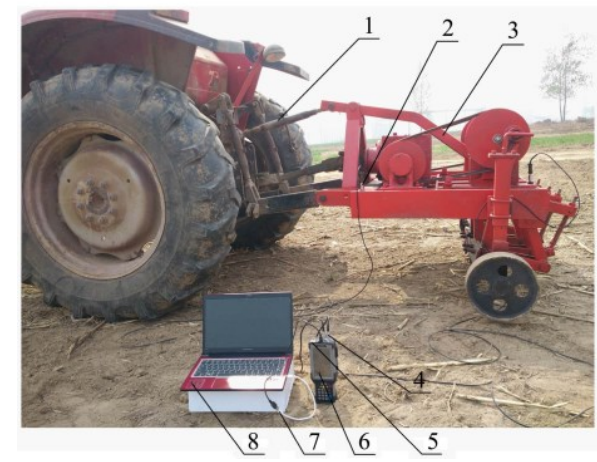

1. Tractor 2. Vibration sensor 3. Aerator 4. Testing channel 5. Infrared sensor 6. Location measurement instrument 7. Communication cable 8. Laptop

Figure 5 Schematic diagram of field testing for aerator ${ }^{[26]}$

In field plots, similar soil condition (same test site) was selected to make a comparison between the initial parameters and optimized parameters of the aerator. The plots were leveled and 
weeded without plowing, and the moisture content was approximately $10 \%$ and $15 \%$ by weight at depth of $0-10 \mathrm{~cm}$ and $10-20 \mathrm{~cm}$, respectively.

\subsection{Experimental design}

The primary goal of the field test was to evaluate the field performance of the aerator with the optimized parameters under the actual tractor's forward speeds. Before field test, the aerator was coupled to a tractor's three-point suspension, and a location measurement instrument was installed on the aerator to monitor the coordinate information.

The aerating performance was studied under 5 forward speed treatments of $3 \mathrm{~km} / \mathrm{h}, 3.5 \mathrm{~km} / \mathrm{h}, 3.7 \mathrm{~km} / \mathrm{h}, 4 \mathrm{~km} / \mathrm{h}$, and $4.7 \mathrm{~km} / \mathrm{h}$, respectively. Each test was repeated 5 times for statistical analysis, with 4 sampling points per group. Overall, for the optimized aerator, a sample of 100 holes was verified to determine the consistency of the depth and inclination angle.

\subsection{Results}

A summary of the descriptive statistics for aerating depth was included in Table 2. When the aerating depth was adjusted to $100 \mathrm{~mm}$, the measured mean value was $99.5 \mathrm{~mm}$ and the coefficient of variability was $4.4 \%$, which indicated that the measured value was concentrated, and close to the target value. According to the industrial standard (LY/T 1605-2002), the basic requirement of holes for aerator was $(100 \pm 10) \mathrm{mm}$ deep, while the maximum error value of the measured value was less than $7 \mathrm{~mm}$, which met the agronomic requirements. Furthermore, the uneven surface of the field would undoubtedly cause the new aerator to have varying depths as the five-bar aerating mechanism operated following a prescribed trajectory. By observation, the $\pm 7 \mathrm{~mm}$ depth could be attributed to the uneven surface.

Table 2 Summary of aerating depth

\begin{tabular}{ccccc}
\hline $\begin{array}{c}\text { Target } \\
\text { aerating } \\
\text { depth/mm }\end{array}$ & $\begin{array}{c}\text { Mean } \\
\text { aerating } \\
\text { depth } / \mathrm{mm}\end{array}$ & $\begin{array}{c}\text { Standard Deviation } \\
\text { of aerating depth } \\
/ \mathrm{mm}\end{array}$ & $\begin{array}{c}\text { Coefficient of } \\
\text { variability } \\
/ \%{ }^{[\mathrm{a}]}\end{array}$ & $\begin{array}{c}\text { Maximum } \\
\text { error } \\
\text { value } / \mathrm{mm}\end{array}$ \\
\hline 100 & 99.5 & 4.35 & 4.4 & 6.7 \\
\hline Note $^{[\mathrm{a}]} n=100$ & & & &
\end{tabular}

Table 3 compared aerating angle from the vertical under different parameter conditions and forward speed treatments. Under optimized parameters condition, mean aerating angle from the vertical decreased from $2.0^{\circ}$ to $1.1^{\circ}$, and then increased to $2.3^{\circ}$ at the forward speed of $3.5 \mathrm{~km} / \mathrm{h}$ to $4.7 \mathrm{~km} / \mathrm{h}$. The maximum hole angle fluctuated from $1.6^{\circ}$ to $3.3^{\circ}$. Furthermore, compared with the initial parameters condition, the mean aerating angle and maximum holes angle decreased by $5.2 \%-47.6 \%$ and $3.8 \%-54.3 \%$ respectively, which demonstrated the improvement for optimized five-bar aerating mechanism using simulated annealing method.

Table 3 Aerating inclination angle from the vertical under different parameter conditions and forward speed treatments

\begin{tabular}{|c|c|c|c|c|}
\hline \multirow{2}{*}{$\begin{array}{l}\text { Forward } \\
\text { speed/ } \\
\mathrm{km} \cdot \mathrm{h}^{-1}\end{array}$} & \multicolumn{2}{|c|}{ Initial parameters ${ }^{[26]}$} & \multicolumn{2}{|c|}{ Optimized parameters } \\
\hline & $\begin{array}{l}\text { Mean aerating } \\
\text { Angle } /\left(^{\circ}\right)\end{array}$ & $\begin{array}{l}\text { Maximum holes } \\
\text { Angle } /\left(^{\circ}\right)\end{array}$ & $\begin{array}{l}\text { Mean aerating } \\
\text { Angle } /\left(^{\circ}\right)\end{array}$ & $\begin{array}{c}\text { Maximum holes } \\
\text { Angle } /\left(^{\circ}\right)\end{array}$ \\
\hline 3.0 & 2.5 & 3.2 & 2.0 & 2.8 \\
\hline 3.5 & 1.9 & 2.6 & 1.8 & 2.5 \\
\hline 3.7 & 1.5 & 2.1 & 1.3 & 2.0 \\
\hline 4.0 & 2.1 & 3.5 & 1.1 & 1.6 \\
\hline 4.7 & 3.3 & 4.3 & 2.3 & 3.3 \\
\hline
\end{tabular}

\section{Conclusions}

(1) To improve the aerating performance for saline-alkali land, an aerator with a five-bar aerating mechanism was proposed, which aimed to realize vertically aerating.

(2) A kinematic model was established to describe aerating process, and related parameters were optimized using a simulated annealing method by Matlab software. Furthermore, computer simulation demonstrated the potential to enhance the perpendicularity property.

(3) The completed machine was tested in field and performed as expected, producing $<7 \mathrm{~mm}$ depth tolerances and $<3.3^{\circ}$ angle tolerances. All the holes were aerated under the speed of 3.5$4.7 \mathrm{~km} / \mathrm{h}$, which verified that the proposed method was more feasible for mechanized farming.

\section{Acknowledgements}

This work was supported by the Interdisciplinary Project of Yangzhou University Crop Science Special Zone (Grant No. yzuxk202007), the Natural Science Foundation of the Jiangsu Higher Education Institutions (Grant No. 20KJB416008), the Key Research and Development Program of Jiangsu Province (Grant No. BE2020319), the Jiangsu Modern Agricultural Machinery Equipment and Technology Demonstration and Promotion Project (Grant No. NJ2020-17), the Program for Innovative Research Team in Ministry of Education of China (Grant No. IRT13039), the Taizhou Science and Technology Infrastructure Program (Grant No. TN201913), and the Nanjing Science and Technology Program (Grant No. 201805062).

\section{[References]}

[1] Yu J, Chen S, Zhao Q, Wang T, Yang C, Diaz C, et al. Physiological and proteomic analysis of salinity tolerance in Puccinellia tenuiflora. Journal of Proteome Research, 2011; 10(9): 3852-3870.

[2] Gao C, Wang Y, Liu G, Yang C, Jiang J, Li H. Expression profiling of salinity-alkali stress responses by large-scale expressed sequence tag analysis in Tamarix hispid. Plant Molecular Biology, 2008; 66(3): 245-258.

[3] Luo S, Wang S, Tian L, Shi S, Xu S, Yang F, et al. Aggregate-related changes in soil microbial communities under different ameliorant applications in saline-sodic soils. Geoderma, 2018; 329: 108-117.

[4] Wang Y, Ma H, Liu G, Xu C, Zhang D, Ban Q. Analysis of gene expression profile of Limonium bicolor under $\mathrm{NaHCO}_{3}$ stress using cDNA microarray. Plant Molecular Biology Reporter, 2008; 26(3): 241-254.

[5] Abdel-Fattah G M, Asrar A W A. Arbuscular mycorrhizal funga application to improve growth and tolerance of wheat (Triticum aestivum L.) plants grown in saline soil. Acta Physiologiae Plantarum, 2011; 34: 267-277.

[6] Trejo A, De-Bashan L E, Hartmann A, Hernandez J P, Rothballer M, Schmid M, et al. Recycling waste debris of immobilized microalgae and plant growth-promoting bacteria from wastewater treatment as a resource to improve fertility of eroded desert soil. Environmental and Experimental Botany, 2012; 75(4): 65-73.

[7] Shi S, Tian L, Nasir F, Bahadur A, Batool A, Luo S, et al. Response of microbial communities and enzyme activities to amendments in saline-alkaline soils. Appl Soil Ecol, 2019; 135: 16-24.

[8] Lippuner V, Cyert M S, Gasser C S. Two classes of plant cDNA clones differentially complement yeast calcineurin mutants and increase salt tolerance of wild-type yeast. Journal of Biological Chemistry, 1996; 271(22): 12859-12866.

[9] Jarvis D E, Ryu C H, Beilstein M A, Schumaker K S. Distinct roles for SOS1 in the convergent evolution of salt tolerance in Eutrema salsugineum and Schrenkiella parvula. Molecular Biology and Evolution, 2014; 31(8): 2094-2107.

[10] Singh Y P, Mishra V K, Singh S, Sharma D K, Singh D, Singh U S, et al. Productivity of sodic soils can be enhanced through the use of salt tolerant rice varieties and proper agronomic practices. Field Crops Research, 2016; 190: 82-90.

[11] Glenn E P, Brown J J, Blumwald E. Salt Tolerance and Crop Potential of Halophytes. Critical Reviews in Plant Sciences, 1999; 18(2): 227-255.

[12] Yamaguchi T, Blumwald E. Developing salt-tolerant crop plants: 
challenges and opportunities. Trends in Plant Science, 2005; 10(12): 615-620.

[13] Liu Y, Yang H, Wang K, Lu T, Zhang F. Shallow subsurface pipe drainage in Xinjiang lowers soil salinity and improves cotton seed yield. Transactions of the CSAE, 2014; 30(16): 84-90. (in Chinese)

[14] Guo G, Araya K, Jia H, Zhang Z, Ohomiya K, Matsuda J. Improvement of salt-affected soils, part 1: interception of capillarity. Biosystems Engineering, 2006; 94(1): 139-150.

[15] Liu C, Li Q, Li X. Effect of deep tillage on amelioration and utilization of soda-alkaline upland fields. Soils, 2007; 39(2): 306-309. (in Chinese)

[16] Liu G, Zhang X, Wang X, Shao H, Yang J, Wang X. Soil enzymes as indicators of saline soil fertility under various soil amendments. Agr Ecosyst Environ, 2017; 237: 274-279.

[17] Yu J, Wang Z, Meixner F X, Yang F, Wu H, Chen X. Biogeochemical characterizations and reclamation strategies of saline sodic soil in Northeastern China. Clean-Soil Air Water, 2010; 38(11): 1010-1016.

[18] Zhao Y, Pang H, Li Y, Hu X, Wang J, Gao H. Effects of straw interlayer on soil water and salt movement and sunflower photosynthetic characteristics in saline-alkali soils. Acta Ecologica Sinica, 2013; 33(17): 5153-5161. (In Chinese)

[19] Njoku K L, Akinola M O, Oboh B O. Growth and performance of Glycine max L. (Merrill) grown in crude oil contaminated soil augmented with cow dung. Life Science Journal, 2008; 5(3): 89-93.
[20] Flury M. Experimental evidence of transport of pesticides through field soils: a review. Journal of Environmental Quality, 1996; 25(1): 25-45.

[21] Mori Y, Iwama K, Maruyama T, Mitsuno T. Discriminating the influence of soil texture and management-induced changes in macropore flow using soft X-rays. Soil Science 1999; 164(7): 467-482.

[22] Mori Y, Hirai Y. Effective vertical solute transport in soils by artificial macropore system. Journal of Hazardous, Toxic, and Radioactive Waste, 2014; 18(2): 1-7.

[23] Atkinson J L, Mccarty L B, Bridges W C. Effect of core aerification frequency, area impacted, and topdressing rate on turf quality and soil physical properties. Agronomy Journal, 2012; 104(6): 1710-1715.

[24] Liu X, Yang C, Xu Y, Tantai G, Jia L, Li T. Effect of aeration on turf and the microbial activity and organic matter of soil. Acta Agrestia Sinica, 2013; 21(1): 174-179. (in Chinese)

[25] Zhang B, Ma C, Ma L, Jia L, Jia Z, Liu H. Mechanism of sand column in improving coastal saline soil. Transactions of the CSAM, 2013; 44(6): 122-127. (in Chinese)

[26] Zhang Y, Li H, Hu H, Chen W, Wang X, Niu Q. Design and experiment on rear suspended passive aerator in saline-alkali land. Transactions of the CSAE, 2016; 32(18): 42-49. (in Chinese)

[27] Zhou M, Sun L, Du X, Zhao Y, Xin L. Optimal design and experiment of rice pot seedling transplanting mechanism with planetary Bezier gears. Transactions of the ASABE, 2014; 57(6): 1537-1548. 